\title{
Educação ambiental e estudo da paisagem: a percepção para a responsabilidade socioambiental
}

\section{Environmental education and study of the landscape: the perception of environmental responsibility}

\author{
Bárbara Cadore Demmer* \\ Yára Christina Cesário Pereira**
}

\begin{abstract}
Resumo: O presente artigo delineia as intervenções pedagógicas realizadas ao longo do Estágio Supervisionado - Pesquisa da Prática Pedagógica, Curso de Ciências Biológicas - Licenciatura Plena, Universidade do Vale do Itajaí, desenvolvido no Programa de Cidadania Socioambiental - SocioAmbientar: Multiplicando Sonhos, que atende crianças e adolescentes em situação de vulnerabilidade social no Município de Itajaí/SC. As ações tiveram como objetivo instrumentalizar o grupo para que, frente à análise de problemáticas socioambientais, tenham autonomia para atuar como agentes transformadores do contexto em que vivem a partir da compreensão das relações de interdependência e complementaridade que existe entre a paisagem natural e a paisagem cultural, abordando o ensino das Ciências Naturais, em sua interdisciplinaridade, como protagonista no processo de formação do sujeito. Nesse contexto, a Educação Ambiental surge como ferramenta para desenvolver a problemática socioambiental de maneira a contribuir para uma reflexão sobre o padrão de comportamento ético e ecológico, recorrente em nosso cotidiano, em busca de uma prática em defesa da qualidade de vida. A Leitura de Paisagem, utilizada como instrumento didático, pauta a criticidade, tendo em vista que sua metodologia pesquisa-ação-participante é desencadeada pelo sujeito efetivamente emergido na construção do processo. Assim, preza-se uma educação que valoriza o diálogo na explicitação dos conhecimentos, em busca de alternativas que considerem o conhecimento científico, o conhecimento popular, as manifestações culturais e uma nova ética nas relações sociedade - natureza. As oficinas geraram resultados efetivos referentes à apreensão dos conceitos e convertidos em atitudes fundamentadas na informação séria e coerente com a realidade local/global.
\end{abstract}

Palavras-chave: Ensino de Ciências Naturais. Educação ambiental emancipatória. Cidadania socioambiental. Leitura de paisagem.

Abstract: This paper outlines the pedagogical interventions carried out during the SupervisedPedagogical Practice Research, Biological Sciences degree course, University of Vale do Itajaí, developed in the Socio-environmental Citizenship program, 'Social and Environmental: Multiplying Dreams', which serves children and adolescents in situations of social vulnerability in the city of Itajaí/SC. The actions were intended to equip the group so that in the face of analyzing social and environmental issues they would have the autonomy to act as agents of change in the context in which they live from the understanding of interdependence and complementarity that exists between the natural landscape and culture, addressing the teaching of Natural Sciences in its interdisciplinarity, as a protagonist in the process of the formation of individuals. In this context, Environmental Education emerges as a tool to develop the socio-environmental problem in order to contribute to a reflection on the

\footnotetext{
* Licenciada em Ciências Biológicas pela Universidade do Vale do Itajaí(UNIVALI). E-mail: < bahdemmer@hotmail.com>.

** Doutora em Educação pela Universidade Federal de Santa Catarina (UFSC). Universidade do Vale do Itajaí (UNIVALI). E-mail: <yara@uniali.br>.
} 
standard of ethical and ecological behavior, recurrent in our daily lives, in search of a practice to protect the quality of life. Reading the Landscape is used as an educational tool in the critical agenda, given that its research-action-participation methodology is triggered by the subject actually emerging in the construction process. Thus, an education is appreciated that values dialogue about explicit knowledge in search of alternatives to consider scientific knowledge, popular knowledge, cultural events and a new ethic in relations between society and nature. The workshops generated effective results regarding the understanding of these concepts and they were converted into actions based on serious information consistent with the local/global.

Keywords: Teaching of natural sciences. Emancipatory environmental education. Socio-environmental citizenship. Reading of landscape.

\section{Introdução: um breve sobrevoo histórico}

Criar uma sociedade que possa ser considerada não apenas ecologicamente responsável, mas também socialmente justa e politicamente atuante, é um desejo que se traduz na busca de uma educação que promova o diálogo e a troca afetiva e efetiva de olhares e saberes, rompendo a visão tradicional e utilitarista, despertando em cada indivíduo o sentimento de pertencimento, integração, participação e responsabilidade. Essa é uma formação que se constrói pelo encontro de saberes, e onde não há necessariamente coisas para serem ensinadas ou explicadas, mas realidades para serem compreendidas e transformadas (FERRARO et al., 2005).

A crise de“eco-sócio-sustentabilidade” instalada sobre nossas necessidades sugere a superação de alguns paradigmas da modernidade e a sua substituição por um desenvolvimento humano sustentável. Para conseguirmos ultrapassá-la, é necessário que nos reconheçamos, enquanto seres humanos pertencentes e atuantes, dentro de quatro esferas: o ser ambientalmente sustentável no uso e preservação dos recursos naturais e da biodiversidade; o ser socialmente sustentável na redução da pobreza e das desigualdades sociais; o ser culturalmente sustentável na preservação dos sistemas de valores que definem a nossa identidade e a identidade regional/nacional através dos tempos; e o ser politicamente sustentável, ao nos aprofundarmos e garantirmos o acesso e a participação de todos na tomada de decisões (GUIMARÃES, 2007). Para tanto, uma reflexão guiada por uma "nova ética” de crescimento precisa ser adotada, na qual a dignidade humana e a melhoria da qualidade de vida das pessoas caminham ao lado do progresso econômico e das leis de funcionamento e respeito dos sistemas naturais. Nessa perspectiva, ética e justiça, tal como ambiente e sociedade, são absolutamente sistêmicas e correspondentes (PELIZZOLI, 2007).

Cortella (2008) nos leva a refletir sobre a ética como uma questão absolutamente humana, "porque a ética parte do pressuposto da possibilidade de escolha, da possibilidade de decisão e da possibilidade de opção”. E ainda ressalva que a ética está ligada à liberdade, assim como o conhecimento com a liberdade, "porque conhecimento tem a ver com ética”. O ser humano, dentro da sua grandiosidade, possui sua inteligência, que só a ele pertence, e por isso não podemos subjugá-lo. Devemos reconhecer que dentro desse conhecimento culturalmente construído é que está a integridade do ser, sua 
transparência, o completo, o inteiro. E dentro dessa perspectiva, outra chamada de atenção se faz necessária: a de nos assumirmos não como seres individuais, mas coletivos, pois assim poderemos manter a integridade do nosso lugar, da nossa casa, para vivermos bem, respeitando a tudo e a todos. A ética é a morada do ser humano, por isso devemos preservá-la e respeitá-la. A conexão da ética com o conhecimento é o que mantém a integridade da vida coletiva, e a "capacidade de dizer não a tudo que vitima e proteger a tudo o que eleva a Vida" (CORTELLA, 2008).

Para acompanhar essa lógica, é importante implementar esforços na elaboração e execução de ações "no e sobre o" meio ambiente, em uma dimensão prospectiva e reconstrutiva por todos os atores do sistema social. Reportamo-nos aos anos 60, quando diversos grupos e organizações não governamentais (ONGs) começam a aparecer e a crescer de forma exponencial. Nesse sentido, na década de 80, o Relatório de Brundtland ${ }^{1}$, também conhecido como "Nosso Futuro Comum", sublinha a interligação entre economia, tecnologia, sociedade e política, e atenta para uma nova postura ética, caracterizada pela responsabilidade tanto entre as gerações quanto entre os membros contemporâneos da sociedade atual. Ou seja, atenta para uma nova filosofia do desenvolvimento que combina eficiência econômica com justiça social e prudência ecológica. Consequentemente, estabelecer um novo patamar de relações sociais depende

\footnotetext{
${ }^{1}$ Esse relatório é o resultado do trabalho da comissão da ONU World Comission on Environment and Development, presidida por Gro Harlem Brundtlandt e Mansour Khalid, daí o seu nome. O documento parte de uma abordagem da complexidade das causas que originam os problemas socioeconômicos e ecológicos da sociedade global.
}

simultaneamente de opções pessoais e de formações sociais que possibilitem tal desejo e necessidade (LOUREIRO, 2007, p. 162).

É imprescindível que, a partir do presente momento, nossa concepção de meio ambiente estilhace a alienação e passe a envolver todas as esferas, com todos os seus elementos vivos e não vivos, relacionando-se e influenciando-se entre si, em um equilíbrio dinâmico. Se não for a partir dessa concepção que repensaremos os nossos valores, eles continuarão fragmentados, afirmando uma consciência individual, deixando de nos sentir verdadeiramente parte integrante de toda a natureza. A separação do ser humano e da natureza se reflete em toda a produção humana, em particular no conhecimento produzido pelo modelo de sociedade historicamente construído pela humanidade. Contudo, o meio ambiente é uma unidade que precisa ser compreendida inteira.

A deterioração do nosso meio ambiente natural tem sido acompanhada de um correspondente aumento nos problemas de saúde dos indivíduos, seja no aspecto nutricional, em doenças crônicas ou degenerativas, psicológicas, ou no recrudescimento de crimes violentos, suicídios, alcoolismo e outras drogas, acidentes de trânsito, etc. Essa epidemia se difunde também no contexto econômico, em um cenário no qual a inflação, o desemprego, a distribuição desigual de renda passaram a ser características banais da economia nacional. Quer fale-se de câncer, criminalidade, poluição, escassez de água, desigualdade social, inflação, a dinâmica adjacente a esses problemas é a mesma. Esses problemas são sistêmicos, o que significa que estão intimamente interligados. Como sugere Capra (1982, p. 15), “uma resolução só poderá ser implementada se a estrutura da própria teia for mudada, o que envolverá transformações profundas em nossas instituições sociais e em nossos 
valores e idéias.” E essas transformações implicam uma fase de reavaliação e de renascimento cultural; logo, de renascimento também social e ambiental.

Ao nos abrirmos para refletir sobre a complexidade da temática socioambiental, outra janela se abre para a compreensão de um novo processo educativo que vem se instalando neste novo século, pautada na lógica que privilegia o diálogo e a interdependência de diferentes áreas de saber. A articulação entre educação, sociedade e natureza, a partir desse momento, passa a permear diferentes caminhos. O preparo científico do professor deve, pois, "coincidir com sua retidão ética" (FREIRE, 1997, p. 08) e ter uma dimensão interdisciplinar, pois assim poderemos assimilar plenamente o equilíbrio dinâmico do ambiente em que vivemos, em conjunto com nossos valores e nossas vontades.

O progresso do pensamento nos mostra a necessidade de aprender a aplicá-lo com base na experimentação das ciências sociais e no domínio das ciências naturais, para conseguirmos maior êxito. A educação tem como objetivo continuar a enriquecer o processo da vida por pensamentos e ações melhores; ela está, portanto, na Vida e para a Vida. Seu objetivo é o único que se adapta a um mundo em desenvolvimento.

Permeando todo esse processo, a disciplina Estágio Supervisionado: Pesquisa da Prática Pedagógica $\left(7^{\circ}\right.$ período do Curso de Ciências Biológicas, Universidade do Vale do Itajaí), desenvolvida junto às crianças e adolescentes do Programa de Cidadania Socioambiental - SocioAmbientar: Multiplicando Sonhos (Itajaí/SC) ${ }^{2}$, colocou-se como materialização das reflexões e discussões ora apresentadas. As atividades desenvolvidas, que serão apresentadas neste artigo, tiveram

\footnotetext{
2 Programa SocioAmbientar: http://socioambientar. ning.com/ - socioambientar@hotmail.com
}

como objetivo principal instrumentalizar o grupo para que, frente à análise de problemáticas socioambientais, possam atuar como agentes transformadores do contexto em que vivem, a partir da compreensão das relações de interdependência e complementaridade que existe entre a paisagem natural e a paisagem cultural. Segundo Nicola (2002, p. 10), entendemos a paisagem como

produto da ação de diversos fatores interrelacionados de modo sistemático, e sua leitura e compreensão dependerá de uma análise integrada destes fatores.

Reforçando a importância da interdisciplinaridade, o autor considera que "a paisagem proporciona um referencial de convergência entre as diversas disciplinas (exatas, naturais ou humanas)".

\section{(Re)Pensar do papel da educação: arquitetando utopias ${ }^{3}$}

“Não é possível refazer este país, democratizá-lo, humanizá-lo, torná-lo sério, com adolescentes brincando de matar gente, ofendendo a vida, destruindo o sonho, inviabilizando o amor. Se a educação sozinha não transforma a sociedade, sem ela tampouco a sociedade muda.”

(Paulo Freire)

Desde sempre a educação existiu. Seu papel fundamental era caracterizado pela transmissão dos hábitos de conduta dos mais velhos para os mais jovens. Com o tempo, a escola adveio como uma bifurcação na educação: aquela aprendida

\footnotetext{
${ }^{3}$ Segundo Paulo Freire (1980, p. 16), “utópico não é o irrealizável; a utopia não é o idealismo, é a dialetização dos atos de denunciar e anunciar, o ato de denunciar o desumanizante e de anunciar a estrutura humanizante. Por esta razão, a utopia é também um compromisso histórico”.
} 
em casa, a linguagem da vida diária, deveres domésticos, costumes morais e sociais; e a outra, com tempo e lugar determinado, com seu conteúdo adequado, cristalizado, de acordo com as necessidades sociais e econômicas de sua época.

Nossa civilização passa por mudanças e vem reformulando, de modo claro, as exigências à educação. $O$ último século assistiu a muitas adaptações e presenciou uma crescente plasticidade de pensamento (KILPATRICK, 1974). Assim, as teorias básicas de educação de toda a sociedade precisam ser reformadas, precisam conter o reconhecimento da própria mudança como elemento essencial. Mudança permanente, rápida e crescente.

Hoje, nos ronda a perplexidade da perda de direção e horizontes. Neste contexto, é fundamental que os profissionais da educação, aqueles que fazem e pensam a educação a cada dia, cultivem e fundamentem as críticas e arquitetem utopias como impulso na construção do novo, no processo de emancipação sócio-antropológica.

A razão de ser da prática social da educação é a contribuição que ela oferece para a construção histórica da transformação humana. No sentido amplo, a educação é o processo concreto de produção histórica da existência humana. Segundo Freire (1997, p. 42), a pedagogia "é um processo que nasce da observação e da reflexão e culmina na ação transformadora”. Portanto, de um lado, a educação tem a função de contribuir para a integração social, a apropriação da cultura; do outro, tem a função de contribuir para a inscrição autônoma e original das pessoas na evolução histórica da humanidade. A educação, em sua especificidade, desenvolve princípios e está centrada na criatividade, na possibilidade do novo, do original. É um processo de construção de possibilidades de ir além do que já existe.
Parafraseando Wittmann (2002, p. 87),

a educação é o lugar privilegiado para a construção e o exercício da parceria e 'companheirice' oportunizados pelo conhecimento, com base nas relações humanas.

Portanto, é na prática educativa, na qual professores e alunos ampliam seus conhecimentos, que brotam as atitudes necessárias para esse emergente mundo novo, humanamente cada vez mais exigente, trazendo à tona a função sociopolítica da educação. O essencial é termos esperança nessa superação, cujos sentidos políticos e econômicos ainda não vislumbramos com clareza, mas que, como desejamos, incluirá a universalização de uma educação para uma cidadania ${ }^{4}$ plena, para a "fruição da cultura, para o trabalho digno" (MENEZES, 2000, p.48).

A educação necessita que sejam resgatados seus valores de forma leve, contemporânea, desafiante, criativa, perseverante e esperançosa, o que demanda do educador um exercício permanente. Como Freire (1997, p. 06) nos ensina, "formar é muito mais do que puramente treinar o educando no desempenho de destrezas", é a convivência amorosa com os alunos e, ao mesmo tempo, provocá-los a se assumirem enquanto sujeitos sócio-histórico-culturais do ato de conhecer, propiciando-lhes dignidade e autonomia. A formação enlaça a epistemologia e a ética, articulando conhecimento e ação, saberes e valores, reflexões e atitudes, teorias e práticas. Assim, cidadão é quem assume a responsabilidade compartilhada de construção da vida da sociedade como condição

\footnotetext{
${ }^{4}$ Segundo as bases do Programa SocioAmbientar, “Cidadão não é aquele que vive em sociedade, mas aquele que a transforma.” (Augusto Boal).

Conceito de Cidadania, construído pelas crianças e adolescentes do SocioAmbientar: "Temos que respeitar uns aos outros, independentemente de classe, cor, religião, cumprir com seus direitos e deveres. Tendo assim uma sociedade feliz, democrática, participativa, que tem amor a natureza”.
} 
necessária para a sua própria construção. "A educação tem como referência a sociedade” (SOBRINHO, 2007, p. 157).

Ainda seguindo os pensamentos de Jacob (apud FREIRE, 1997), somos "seres programados, mas, para aprender". Viemos descobrindo, ao longo dos tempos, que o ensinar pode não ser uma tarefa meramente embutida no aprender, mas pode ser um processo que deflagra no aprendiz uma curiosidade crescente, que pode torná-lo mais e mais criador. Ou seja, a curiosidade epistemológica, exercida através da criticidade, configura-se na curiosidade não facilmente satisfeita, que supera os efeitos negativos do falso ensinar.

O professor tem um papel fundamental em toda essa discussão e isso demanda uma reflexão crítica sobre a prática da didática, para poder melhorar a prática do amanhã. Para haver a mudança na educação que tanto se esmera, faz-se necessário o processo de mudança também do sujeito enquanto docente, promovendo a busca de um novo compromisso: o emocional. Nenhuma formação docente verdadeira pode fazer-se alheia ao exercício da criatividade, o qual implica a promoção da curiosidade ingênua à curiosidade epistemológica, e o reconhecimento do valor das emoções, da sensibilidade e da afetividade. Como afirma Wittmann (2002, p. 96), "urge reinventar a educação, o sonho, a alegria, na construção do novo, da parceria e da emancipação".

\section{O ensino das Ciências Naturais como construção humana}

A sede de conhecimento atual depara-se com as necessidades reais do ser humano, seus problemas e contradições. Dessa forma, tornam-se necessárias contribuições de diversos ramos do conhecimento e do intercâmbio entre seus representantes. Não seria possível à Educação em Ciências afirmar-se como área científica disciplinar em construção progressiva sem estar fortemente articulada com outros campos disciplinares.

Analisando-se do ponto de vista epistemológico, a interdisciplinaridade baseia-se em um método de pesquisa, na troca de experiências e de ensino que enfoca a interação de duas ou mais áreas do conhecimento. Leff (apud CARNEIRO, 2007, p. 100) traduz a interdisciplinaridade da seguinte forma:

A articulação integrativa de disciplinas e saberes na construção partilhada do conhecimento ante problemas socioambientais - com desconstrução do pensamento disciplinar e reconstrução de novos sentidos do ser e de ser no mundo.

Complementando, Capra (1982, p.08) afirma que nossa sociedade vive "em um mundo globalmente interligado, no qual os fenômenos biológicos, psicológicos, sociais e ambientais são todos interdependentes”. Diante dessa visão integradora de mundo, é possível destacar o papel das Ciências Naturais $(\mathrm{CN})$ enquanto protagonista do processo de formação humana, no que diz respeito tanto à ciência ambiental quanto à ciência social. E essa confluência é justificada quando dizemos que não há possibilidade de se pensar na questão ambiental sem se fazer presente o social, assim como não há como pensar na educação, sem pensar no humano. De uma forma muito significativa, Sobrinho (2007, p. 161) argumenta:

A construção do conhecimento está ligada a experiência e a formação do sujeito. A formação carrega a dimensão da solidariedade, entendida fundamentalmente como prática social da responsabilidade pública. (...) O conhecimento como bem 
público beneficia o coletivo e amplia a inclusão. O conhecimento, enquanto bem público, que se insere na perspectiva da solidariedade como responsabilidade compartilhada, não se desgasta nem se corrói; ao contrário, se enriquece a medida que enlaça e incorpora cada vez mais novos sujeitos cognoscentes e ajuda a consolidar a convivialidade.

Ao envolver problemáticas sociais e econômicas, o ensino das $\mathrm{CN}$ se aproxima do ensino das Ciências Humanas e Sociais, reforçando a ciência como construção humana. Nesse sentido, os valores humanos não são alheios ao aprendizado das ciências, e apontam-se como um novo instrumento de construção crítica. Segundo Loureiro (2005, p. 326),

[...] teoria tradicional é toda aquela que se produz como válida pela ciência dominante. Suas características ignoram o movimento da historia, os sujeitos e a ciência como prática social inserida em um conjunto complexo de relações sociais e suas implicações econômicas, políticas, ideológicas e de poder. Romper com essas características conservadoras e adotar um posicionamento de permanente questionamento com vistas a construir conhecimentos que sirvam para a emancipação e para a transformação da sociedade é a finalidade primeira e última da Teoria Crítica.

Outra prática que vem sendo muito importante para o ensino das $\mathrm{CN}$, e que cada vez mais assume seu papel, trabalha na perspectiva de trazer para a sala de aula a atividade científica, em um movimento de aproximar os conhecimentos científicos dos conhecimentos escolares. E essa prática vem acompanhada de novas linguagens, que além de contribuírem com sua nomenclatura para as linguagens usuais, se constituem em linguagens especificas com códigos próprios, inseparáveis das formas de pensar científicas. Para isso, o diálogo entre os alunos, mediado pelo professor, é essencial, pois é quando o aluno reelabora sua percepção anterior de mundo, ao entrar em contato com a visão trazida pelo conhecimento científico. Para fundamentar esse pensamento, Krasilchik (apud TRÓPIA, 2009, p. 05) afirma o seguinte:

Na medida em que a Ciência e a Tecnologia foram reconhecidas como essenciais no desenvolvimento econômico, cultural e social, o ensino das Ciências em todos os níveis foi também crescendo de importância, sendo objeto de inúmeros movimentos de transformação do ensino, podendo servir de ilustração para tentativas e efeitos das reformas educacionais.

Ainda, Abd-El-Khalick et al. (apud TRÓPIA, 2009, p. 07) aponta sete aspectos que considera necessário discutir para conceber o ensino de ciências. São eles:

(a) aprender ciência versus aprender sobre ciência; (b) ciência como busca da verdade versus ciência como atividade de resolução de problemas; (c) levantar e responder questões versus propor e revisar explicações e modelos; (d) ciência como atividade cognitiva versus ciência como atividade social; (e) demonstração de conceitos versus investigação de como sabemos e por que acreditamos nisso; (f) ciência hipotético-dedutiva versus modelo baseado em ciência; (g) ciência como processo de justificar e testar conhecimentos versus ciência como processo de descoberta e generalização de conhecimentos.

Assim, as concepções atuais do ensinar as Ciências Naturais buscam compreender a natureza da investigação científica, a fim de levar aos alunos a sua apreensão para que desenvolvam uma apurada percepção, 
pois a sociedade carece de cidadãos que tenham propriedade para participar com eficiência em decisões políticas e interpretar o significado das novas implicações científicas em suas vidas. É preciso que os cidadãos compreendam a ciência, seus poderes e limites, não porque isso é bom para a ciência, mas porque isso é crucial para a democracia (TRÓPIA, 2009, p. 08). A ciência, potencialmente, pode trazer o poder para a tomada de decisões. Trata-se, portanto, de contextualizar e humanizar o estudo das $\mathrm{CN}$, para que mais facilmente e mais cedo se desperte $\mathrm{o}$ gosto pelo mesmo.

O conceito tradicional de Ciência como uma natureza autônoma e com uma legalidade que se impõe de forma absoluta, de sentido autoritário, reducionista e determinista, não tem mais sentido para a sociedade. Faz-se urgente a valorização da verdadeira percepção do conhecimento científico, envolvendo sempre na sua construção uma confrontação com o mundo diligente, probabilístico, replicável e humano - feito por seres humanos e para seres humanos. A Ciência é parte inseparável de todas as outras componentes que caracterizam a cultura humana, tendo, portanto, implicações tanto nas relações ser humano-natureza como nas relações ser humano- ser humano.

Temáticas ligadas à cultura, à paz (não violência), à ecologia, à democracia, à identidade, à complexidade, ao tempo, ao espaço possuem natureza interdisciplinar. Não se esgotam nem podem ser abordadas sob uma perspectiva disciplinar, podendo ter seus campos interpretativos reduzidos e empobrecidos, pois se trabalhadas de forma aprofundada e articulada com a realidade, representam excelentes possibilidades de constituírem-se em temas geradores para os currículos escolares (NOAL, 2002).

\section{Contribuições da educação ambiental no processo construtivo social}

Em um contexto marcado pela degradação permanente do meio ambiente e do seu ecossistema, a reflexão sobre as práticas sociais cria uma necessária articulação com a produção de sentidos sobre a Educação Ambiental (JACOBI, 2003). Pensar em Educação Ambiental (EA) não é só pensar na dimensão ambiental propriamente dita. Um desafio maior permeia as discussões recorrentes a esse processo. O desafio corrobora a formulação de uma EA que seja crítica e inovadora em seus níveis, seja formal e/ou não informal, estando voltada para a prática da política social, que almeja a autoaprendizagem e potencializa a sua comunhão. Para tanto, a relação homem versus natureza versus universo tende a perpetuar sob a perspectiva da ação holística, tendo como referência o fato de que os recursos naturais se esgotam, e o principal responsável pela degradação desses recursos é o ser humano.

A EA possui uma convergência disciplinar que justifica seu conceito como temática interdisciplinar, sendo reconhecida principalmente no campo das Ciências Naturais e das Ciências Sociais. Segundo a Conferência Intergovernamental de Educação Ambiental, realizada em Tbilisi em 1977, a EA não é uma

[...] matéria acessória que se soma aos programas existentes, pois exige uma cooperação entre as disciplinas tradicionais, indispensável para poder se perceber a complexidade dos problemas do meio ambiente e formular uma solução. (GAUDIANO, 2005, p. 125)

O avanço na construção da EA tanto importa na teoria da interpretação quanto na busca de uma prática social adequada, propondo um envolvimento em defesa da qualidade de vida. 
Aprender e iniciar-se na EA significa começar a refletir a partir de problemas que nosso próprio cotidiano, nosso modo de vida, nossa razão, nossos questionamentos nos colocam. Assim, a Ecopedagogia ${ }^{5}$, em seu contexto, está atrelada à proposta da EA que defendemos e queremos difundir, pois ela busca a formação de cidadãos preocupados com a qualidade do seu futuro. Como pedagogia freiriana, ela visa empoderar os cidadãos e formar o cidadão do mundo. Empoderar no sentido de trazê-los a uma abordagem educativa emancipatória, crítica e transformadora, de forma transcendental, sem limites, em busca da experiência, do conhecimento, da razão.

A ecopedagogia pode ser vista como uma pedagogia da luta pela solidariedade, preocupada com o sentido da vida cotidiana das pessoas. Uma pedagogia do afeto, que declara seu amor ao planeta e ao próximo, por um compromisso pessoal de cuidar dele com afabilidade e responsabilidade, buscando nos ensinar o modo de gerir a nossa casa com sabedoria (GADOTTI, 2003), nos apropriando da cultura da sustentabilidade. A preocupação com o desenvolvimento sustentável ${ }^{6}$ representa a possibilidade de

\footnotetext{
5 “A ecopedagogia não é uma pedagogia a mais, ao lado de outras pedagogias. Ela só tem sentido como projeto alternativo global onde a preocupação não está apenas na preservação da natureza (Ecologia Natural) ou no impacto das sociedades humanas sobre os ambientes naturais (Ecologia Social), mas num novo modelo de civilização sustentável do ponto de vista ecológico (Ecologia Integral) que implica uma mudança nas estruturas econômicas, sociais e culturais. Ela está ligada, portanto, a um projeto utópico: mudar as relações humanas, sociais e ambientais que temos hoje. Aqui está o sentido profundo da Ecopedagogia, ou de uma Pedagogia da Terra, como chamamos”. (GADOTTI, 2000).

${ }^{6}$ Definição para desenvolvimento sustentável segundo a Comissão Mundial sobre Meio Ambiente e Desenvolvimento (ONU): é o desenvolvimento capaz de suprir as necessidades da geração atual sem compro-
}

garantir mudanças sociopolíticas que não comprometam os sistemas ecológicos e sociais que sustentam as comunidades. Num sentido abrangente, a noção de desenvolvimento sustentável reporta-se à necessária redefinição das relações entre sociedade humana e natureza; e, portanto, a uma mudança substancial do próprio processo civilizatório, introduzindo o desafio de pensar a passagem do conceito para a ação.

A introdução da EA no contexto da aprendizagem proporciona um recorte construído social e historicamente como produto de movimentos e lutas sociais. O que se quer destacar é que não se constituiu esse recorte para se estudar a realidade de outro ponto de vista, mas para se intervir nela, questionando o mundo em que vivemos, para reformá-lo através da ação transformativa, que nos faz perceber o problema e buscar soluções para tal. Trata-se de um jeito de olhar a realidade que vem carregada de valores assumidos e de atitudes propostas, assim como de atitudes já tomadas.

Esse momento deve ser encarado como crucial à formação da autonomia do sujeito, ingrediente imprescindível na formação de um cidadão. Os alunos estão se formando, é preciso discussão e contraposição. O potencial crítico do ser humano é criador e não repetidor, pois o horizonte da crítica é sempre aberto e infinito, e não termina num projeto dado. Segundo Reigota (apud JACOBI, 2003), a EA aponta para propostas pedagógicas centradas na conscientização, mudança de comportamento, desenvolvimento de competências, capacidade de avaliação e participação dos educandos. Complementando, Pádua e Tabanez (apud JACOBI, 2003, p. 195) sugerem que

meter a capacidade de atender as necessidades das futuras gerações. É o desenvolvimento que não esgota os recursos para o futuro. 
a EA propicia aumento de conhecimentos, mudança de valores e aperfeiçoamento de habilidades, condições básicas para estimular maior integração e harmonia dos indivíduos com o meio ambiente.

A partir desta discussão, vamos relembrar que a questão ambiental jamais deverá ser tratada como algo destacado das dimensões sociais e econômicas do mundo em que vivemos, e jamais será tratada, portanto, como uma simples preservação pontual da natureza. Esses são os valores centrais da EA, fundamentais para a formação do cidadão, proporcionando o estímulo para pensarmos em projetos, em intervenção e participação na vida global, para combatermos a indiferença, as injustiças, as atitudes desumanas e cruéis.

Quando concentramos esforços em uma EA emancipatória, a situamos em um contexto mais amplo, o da educação para a cidadania, prosperando o fortalecimento da cidadania para a população como um todo, e não para um grupo restrito, empoderando cada pessoa, a fim de ser portadora dos direitos e deveres, denotando-se como ator corresponsável na defesa da qualidade de vida. A EA pode contribuir muito nesse processo de formação para a cidadania ambiental, pois se configura como uma educação voltada para o resgate de uma relação harmoniosa e de respeito entre a sociedade e o seu meio ambiente. Com isso, ela está ligada à cidadania ambiental, que preconiza uma postura ativa e solidária para a proteção do meio ambiente, enquanto condição para a realização dos demais direitos que integram o conteúdo da cidadania (OLIVEIRA et al., 2008).

Cidadania tem a ver com a identidade e o pertencimento a uma coletividade. A EA perpassa o processo de construção social como exercício e formação de cidadania baseada numa "nova” ética, que designa
- ou (por que não) resgata - valores morais e uma forma integradora de ver o mundo e os homens. A problemática socioambiental propõe a participação democrática da sociedade no processo de tomada de decisões para a construção de futuros possíveis, sob a ótica da sustentabilidade ecológica e da equidade social. Dessa forma, torna-se cada vez mais necessário consolidar novos paradigmas educativos, centrados na preocupação de iluminar a realidade desde outros ângulos, e isso supõe a formulação de novos objetos de referência conceituais e, principalmente, a transformação de atitudes (JACOBI, 2003, p. 192).

\section{Campo de intervenção: Programa de Cidadania socioambiental - Socio- Ambientar: multiplicando sonhos ${ }^{7}$}

O SocioAmbientar é um Programa de Cidadania Socioambiental voltado a sensibilizar e educar crianças e adolescentes para as questões referentes à sociedade e ao meio ambiente. Esse Programa surgiu da união de três pessoas - a engenheira ambiental Maiti Mattoso Fontana, o advogado Eduardo Alexandre dos Santos e a psicóloga Nilcéia Gregório dos Santos - e, consequentemente, de três histórias e um sonho em comum: "Mudar o Mundo" por meio da ação voluntária com oficinas pedagógicas sobre questões socioambientais, junto à Associação Pró-Menor Lar Padre Jacó (Itajaí - SC), que atende o público infantojuvenil em situação de vulnerabilidade social.

A missão do Programa é despertar a importância da cidadania socioambiental, o

\footnotetext{
${ }^{7}$ Texto escrito por Maiti Mattoso Fontana, idealizadora do programa, e cedido pela coordenação do Programa de Cidadania Socioambiental - SocioAmbientar: Multiplicando Sonhos. Adaptado pela autora do artigo.
} 
exercício de direitos e deveres, sensibilização e percepção ambiental e noções de sustentabilidade. Seus objetivos consistem em contribuir para a construção de uma consciência socioambiental nas crianças e adolescentes atendidos, por meio de oficinas pedagógicas e ecopedagógicas fundamentadas na construção do conhecimento, e colaborar na capacitação de multiplicadores da transformação socioambiental.

Ao longo de três anos e meio, o Programa SocioAmbientar vem recebendo assessoria informal do Programa de Formação para a Cidadania Infanto-Juvenil - PFCIJ (sua origem e base pedagógica), desenvolvido pelo CEJURPS/UNIVALI, onde é fornecido o material didático-pedagógico Caderno da Cidadania ${ }^{8}$ e o suporte técnico subsidiado pelas Diretrizes Teóricas do Caderno de Cidadania, o qual tem sua base teórica fundamentada nos princípios de Paulo Freire e Pedro Demo, na autonomia do educando e no exercício da cidadania.

O Caderno da Cidadania foi construído, aprimorado e aplicado ao longo de dez anos junto às escolas públicas, associações e instituições no município de Itajaí e em experiência piloto em outras regiões do Brasil. Essa atuação vem demonstrando resultados positivos junto aos seus parceiros, com exemplos de construção da cidadania ativa ao longo da infância, adolescência e juventude em diferentes realidades sociais, apontando possibilidades e caminhos para o alcance da sustentabilidade individual e coletiva, ou seja, uma sustentabilidade pautada na qualidade socioambiental.

Por meio de oficinas ecopedagógicas, seja na teoria ou na prática, os atendidos poderão aprender como se desenvolve um cidadão ativo, e a construir sonhos individuais e coletivos a serem realizados. E, ainda, poderão ter a oportunidade de identificar como os recursos naturais são fundamentais à sobrevivência da vida, e que é possível promover uma transformação social através do exercício da cidadania.

A principal motivação do Programa se mostra na possibilidade de os sujeitos envolvidos nesse processo se tornarem multiplicadores da cidadania socioambiental, tornando os conhecimentos acessíveis a um maior número de pessoas que também se encontram em situação de vulnerabilidade e risco social, em uma dimensão muito além da carência econômica. Entre outros tipos de carência, essas pessoas geralmente apresentam desnutrição, condições precárias de habitação e saneamento, subemprego, subconsumo, falta de integração e suporte familiar, e baixos níveis educacionais e culturais. Outra motivação é possibilitar a participação dos pais e responsáveis no processo de capacitação e formação dessas crianças e adolescentes, ainda que de forma indireta, porém efetiva.

O Programa SocioAmbientar vem se tornando um instrumento capaz de fomentar sonhos e utopias, sendo assim uma alavanca para que as crianças e adolescentes que dele participam superem a situação em que se encontram e conheçam os instrumentos necessários para que possam ser capazes de transformar seu destino, reconhecendo a importância da cidadania socioambiental para a construção de um futuro melhor em um âmbito individual e coletivo, pois ensinar é "[...] criar as possibilidades para sua produção ou sua construção” (FREIRE, 1997).

\footnotetext{
${ }^{8}$ OLIVEIRA, A.C.D.C., et al. Diretrizes teóricas do Caderno de Cidadania: Cidadania e Direitos Humanos, Estatuto da Criança e do Adolescente e Cidadania Ambiental. Florianópolis: ALESC, 2008.
}

Olhar de professor, Ponta Grossa, 14(2): 255-272, 2011. Disponível em <http://www.revistas2.uepg.br/index.php/olhardeprofessor> 


\section{As intervenções realizadas}

No campo da educação, as metodologias que classicamente expressam as posições da perspectiva crítica são as de cunho participativo (pesquisa-ação participante, pesquisa participante, investigação-ação, investigação militante, etc.). No Brasil, essas variações se traduziram na utilização intensa da pesquisa participante, tradicionalmente vinculada à educação popular, e na pesquisa-ação-participante, denominação comum entre educadores ambientais (LOUREIRO, 2003). A Leitura de Paisagem ${ }^{9}$, como instrumento didático, muito tem a ver com a criticidade, pois sua metodologia de pesquisa-ação-participante é totalmente evidente, desde os primeiros passos, tendo em vista que todo o seu processo é desencadeado tendo o "público" efetivamente como seu ator principal, determinante de todo o processo construtivo.

Segundo Nicola (2002, p. 11):

A Leitura de Paisagem potencializa a utilização de metodologias que procurem identificar, interpretar, delinear e definir características de uma dada paisagem, a partir da análise de seus componentes, considerados de modo sistêmico, com a participação das populações locais.

Neste trabalho, o estudo da paisagem foi realizado a partir da percepção, que se caracteriza por um processo individual, de forma subjetiva. Entender as relações entre

\footnotetext{
${ }^{9}$ Atividade sistematizada por PEREIRA, Y.C.C., a partir de contribuições de diversos referenciais na disciplina do Estágio Supervisionado: Pesquisa da Prática Pedagógica, em questão. Fonte: CARVALHO, Pompeu Figueiredo de. Impactos ambientais em paisagens urbanas: subsídio a uma nova urbanização. Disponível em http://www.seb-ecologia.org.br/forum/ art24.htm. Acesso em: 02/05/ 2010; DEL RIO, V., 1996; MARENZI, R.C., 2005.
}

o ser humano e a natureza por meio da percepção da paisagem é procurar compreender as atitudes do homem com o ambiente, que traduzem usos, hábitos, valores e expectativas. Seguindo essa linha de pensamento, a percepção ambiental também pode ser um indicativo da dinâmica da interdependência e complementaridade, ou seja, das relações que se estabelecem entre o todo. Assim, pode-se estabelecer uma tentativa de compreensão global dos problemas e processos socioambientais, formando cidadãos conscientes.

As estratégias de intervenção tiveram como foco a percepção quanto aos aspectos socioambientais a partir das esferas da sustentabilidade ${ }^{10}$, a tradução do conhecimento teórico apreendido em ação e a integração do conhecimento à capacidade crítica. As atividades desenvolvidas serão apresentadas a seguir, com um breve comentário sobre o vivido.

Tendo a intenção de instigar as crianças e adolescentes, as atividades foram iniciadas com uma roda de conversa na qual fizemos a explanação dos objetivos das atividades, dando ênfase aos conceitos de interdependência e complementaridade, além da discussão de outros conceitos básicos utilizados em nosso cotidiano, tais como: desenvolvimento sustentável, qualidade de vida, espaço urbano, ambiente natural, preservação ambiental, etc. Também abordamos alguns aspectos históricos relacionados ao Bairro Fazenda - Itajaí (SC), onde reside a maioria dos participantes do Programa, com a utilização de fotos que permitiram a contextualização retrospectiva da história do bairro e da cidade. De acordo com Franco et

\footnotetext{
10 Segundo Guimarães (2007), as quatro esferas da sustentabilidade são compostas pelo ser ambientalmente sustentável, o ser socialmente sustentável, o ser culturalmente sustentável e o ser politicamente sustentável.
} 
al. (2006, p. 2), a percepção visual é a forma mais objetiva de interação do homem com o meio que o cerca; os estímulos visuais atendem perfeitamente aos objetivos da educação. Antes mesmo da escrita, a comunicação visual, valendo-se da percepção visual, ajuda a escrever a história da humanidade. Neste caso, em especial, não seria possível permitir a observação da realidade, a percepção da história e a mobilidade territorial sem a utilização da fotografia.

Partindo das discussões e reflexões realizadas nessa etapa, outro momento se colocou - o desenho da paisagem, quando cada criança e adolescente desenhou uma paisagem, não necessariamente real, a partir da sua percepção, fazendo uso da imaginação, buscando traduzir como o ambiente se estrutura. Essa atividade se destaca de forma muito pertinente, pois nos traz "a visão da visão de cada pessoa”, dando condições de diagnosticar como se configura a sociedade no meio em que vive. Schmithuesen (apud TROPPMAIR, 2000) analisa e caracteriza o que deve ser pesquisado numa "paisagem natural" em que não houve interferência antrópica e que hoje praticamente não existe mais. A problemática ecológica refere-se, nesse caso, ao estudo das relações entre flora e fauna, suas formas de vida, estrutura e dinâmica das biocenoses e bioformações, sucessões, gênese e biotipos. Numa "paisagem cultural” destaca-se a interferência do homem que projeta, executa e organiza o espaço obtendo resultados que o afetam de forma positiva ou negativa, conforme variam as escalas espaciais, a intensidade e a forma de intervenção. A paisagem cultural compreende condições ecológicas e sociais específicas, que nos conduzem à complexa Ecologia Humana, à Ecologia Social.

Na sequência das intervenções fez-se uso de dois vídeos: o primeiro vídeo apresenta uma entrevista com uma moradora do
Bairro Fazenda - Itajaí (SC), falando sobre a História de Itajaí, e o segundo refere-se à Sustentabilidade na cidade de Itajaí ${ }^{11}$. Ambos se tornaram uma ferramenta muito importante, pois foram histórias trazidas com abordagem direta sobre a realidade da cidade onde residimos, cada um dentro de seus objetivos, mas integrando-se de forma substancial. Durante a atividade, fomos criando diálogos sobre o significado das imagens apresentadas nos vídeos, procurando identificar em cada cena particularidades e aspectos gerais do nosso dia-a-dia. Após a abordagem dos vídeos, retomamos conceitos e reflexões que perpassaram os diferentes momentos da intervenção, resgatando assim o sentido e o significado dos conceitos considerados essenciais para o alcance dos nossos objetivos.

Para "garantir" a apropriação desses conceitos essenciais foi proposta uma atividade dinâmica, cuja metodologia se desenvolveu a partir da utilização de imagens retiradas de revistas. A turma foi dividida em três grupos, cada grupo ganhou um envelope contendo diversas imagens e palavras-chave, as quais deveriam ser relacionadas e agrupadas, conforme o contexto que se afigurava. Essa estratégia foi tomada como forma de diagnosticar dúvidas e equívocos conceituais, servindo como embasamento teórico para as atividades que estavam por vir:

Questionário (pesquisa de campo) aplicado junto aos moradores da comunidade local, no bairro Fazenda, Itajaí/SC, relacionando o passado e o vivido no presente, a fim de diagnosticar as principais mudanças ocorridas no contexto socioambiental, identificando as possíveis causas e consequências dessas mudanças, e ainda traçando o perfil dos moradores e reconhecendo suas particularidades.

\footnotetext{
${ }^{11}$ Sustentabilidade na cidade de Itajaí. Disponível em http://www.youtube.com/watch?v=iWfIv6ewFo8. Acesso em 12/05/2011.
} 
b) Saída a campo no entorno da Unidade "Lar Padre Jacó”, Bairro Fazenda (Itajaí - SC), onde cada criança e adolescente fotografou, de acordo com sua concepção, lugares urbanos atribuídos em três categorias (propostas pela autora da atividade): sistema natural sem intervenção antrópica, sistema natural com intervenção antrópica e/ou com degradação, e sistema construído. A turma foi dividida em grupos, cada um seguindo para um ponto diferente, no entorno da entidade. O objetivo dessa etapa foi inferir hipóteses sobre o modo como cada um se relaciona com o meio ambiente, e o que percebe e valoriza. Esse processo foi muito construtivo. A liberdade de expressão possibilitou a cada sujeito expressar seus conhecimentos, sua sensibilidade, suas emoções, sua forma de ser e estar no mundo, suas crenças e esperanças na construção de suas próprias utopias.

c) Através da discussão obtida a partir das fotografias e das entrevistas, partimos para a última, porém não menos importante etapa, a representação do cenário projetivo. Em uma roda de conversa, as crianças e adolescentes foram estimulados a compartilhar os pontos que mais os incomodavam dentro da realidade vivida. Essa discussão foi um momento muito rico, possibilitando o inicio da construção do nosso cenário projetivo, tendo os pontos negativos sinalizados. Partindo do pressuposto de um ambiente com planejamento urbano, com todas as informações obtidas ao longo das oficinas, e conforme as necessidades percebidas pelas crianças e adolescentes, foi possível constituir uma nova projeção para a paisagem construída e a natural.

A Leitura de Paisagem possibilitou o caminhar sobre a teoria de uma forma descontraída, agradável e produtiva, gerando significados incontáveis e estimulando o papel do sujeito crítico, enquanto formador de opinião em uma sociedade não atuante. Podemos identificar valores morais que configuram a identidade de cada ser humano envolvido nessa caminhada e viabilizar momentos de troca de saberes cotidianos e científicos, guiadas por um roteiro de questionamentos, trazendo o diálogo como ferramenta insubstituível na partilha do saber. Estimulamos a percepção daquelas crianças para a sua responsabilidade na criação e manutenção dos espaços urbanos, tanto quanto na preservação e manutenção dos espaços naturais e culturais, pois, antes de querer modificar o mundo presente ao nosso redor, é necessário que ocorra a mudança individual, interior e coletiva. E, para isso, é preciso conhecer e ter disposição para aprender, revendo nossas próprias premissas.

\section{Considerações finais}

O momento de transição pelo qual a humanidade passa traduz uma crescente necessidade de atualização de conhecimento. Se a escola sempre esteve presente de forma a atender necessidades econômicas e sociais de sua época, o presente requer uma atenção maior: a humanização escolar, ou seja, trabalhar com as emoções, dando valor ao sujeito, seu conhecimento, sua tradição, sua cultura, enxergando no outro não somente mais um, mas um ser único e especial, com pensamento próprio, advindo de uma bagagem construída através de sua trajetória. Portanto, percebemos que é dentro da escola que boa parte da formação do sujeito se constitui. E, por assim dizer, a função da educação é primordial para que se possa impulsionar o educando a uma prática cidadã mais consciente e convicta da necessidade de começarmos a avançar da teoria para a ação, para 
que possamos viver de forma harmoniosa e conjunta ao meio-ambiente.

Dentro dessa perspectiva, o contexto de discussão da Educação Ambiental, seja em ambiente formal ou não-formal, tem potencial multifatorial, envolvendo desde as problemáticas sociais e econômicas até as científicas e ambientais, abrindo horizontes que permeiam todas as esferas da sustentabilidade, avigorando a construção do ser humano dentro da criticidade, capaz de adotar um posicionamento que leve à emancipação e transformação da sociedade. Assim, o ensino das Ciências Naturais cresce em sua importância, podendo inferir-se na reforma educacional. A natureza interdisciplinar, que caminha lado a lado das $\mathrm{CN}$, evidencia de forma profunda e articulada as riquezas que a educação guarda em seu seio, possibilitando a compreensão de mundo globalmente interligado, protagonizando o processo de formação humana.

Esse pressuposto se enquadra nos desígnios da Educação Ambiental, a qual empodera o sujeito na busca do conhecimento de forma crítica, em prol da sustentabilidade, questionando e buscando soluções, a fim de resgatar a relação harmoniosa e de respeito entre a sociedade e seu meio, buscando novos paradigmas educativos. Portanto, acreditamos na EA e no seu papel fundamental na construção da cidadania, visto que ela possibilita a formação de atitudes ecológicas e sociais, e torna real e possível construir e estender à comunidade e às gerações futuras o conhecimento, a mudança de valores e a transformação de atitudes.

Quanto ao papel do educador, precisamos ter consciência da responsabilidade que assumimos ao adentrar em um espaço educativo, seja ele formal, informal ou não-formal, sem distinção de credo, cor ou classe social. Parece-nos que ainda não estamos no patamar da prática pautada na igualdade, na solidariedade e no amor. Não seja por menos, pois é difícil mudar a configuração social que vem sendo imposta há séculos. Entretanto, a consciência pela efetiva mudança está sendo semeada, e não é possível que, enquanto educadores, continuemos aceitando o que é imposto pelo sistema corrupto e perverso. É preciso abrirmos nossos olhos, cabeça e coração, e trabalharmos pelo bem comum, a fim de discutir o papel da educação na sociedade, tratando de contextualizar e humanizar a educação. À medida que nós, educadores, formos batalhando por uma educação fundamentalmente pautada na prática social responsável, enquanto bem público, poderemos vir a ser uma sociedade coesa, enriquecida, consciente e vivente, coletiva e inclusa. O Estágio Supervisionado proporciona uma vivência que faz compreender a prática da educação como essencial e privilegiada no processo de formação pessoal, assim como na formação da identidade profissional, sensibilizando o processo construtivo crítico/autocrítico, exigente e igualitário.

Com a prática desenvolvida, esperamos ter deixado para as crianças e adolescentes participantes do Programa SocioAmbientar uma semente que os faça perceber a importância de nos identificarmos como pertencentes ao meio, dentro da visão de interdependência e complementaridade. Esse processo proporcionou aos sujeitos a troca de conhecimentos através de discussões sobre educação e sociedade, transpondo muros, com novas linguagens, novas posturas, novos horizontes, novas possibilidades de visão de mundo. O diálogo, mais uma vez, mostrou-se, por excelência, como uma ferramenta poderosa que permite a partilha, a ressignificação e a produção de saberes, em cada tempo e contexto. Um pequeno

Olhar de professor, Ponta Grossa, 14(2): 255-272, 2011. 
exercício de troca de saberes e experiências que enriquece quem dele participa e permite avaliar em que grau os conhecimentos e saberes estão sendo trocados.

Faz-se importante ressaltar a condição de espaço educativo não-formal que caracteriza o campo de intervenção. Esse campo educacional, por si, torna não obrigatória a presença efetiva dos participantes em todos os encontros. Esse olhar enfatiza a significância que o Programa SocioAmbientar e as intervenções, por nós aplicadas, apresentaram na transformação de mundo de cada um dos 11 corações que compõem o grupo. Em cada encontro em que estivemos acompanhadas dos multiplicadores do SocioAmbientar, a responsabilidade, carregada de amor e sonho, permitiu o sentimento de "missão cumprida”. Um dos afazeres mais significativos da prática educativo-crítica, segundo Freire (1997), é propiciar as condições em que os educandos ensaiam a experiência profunda de assumir-se. Assumir-se como ser social e histórico, transformador, realizador de sonhos.

Não se deve transmitir soluções, mas métodos, atitudes críticas, a fim de criar apreciação inteligente dos próprios problemas, bem como dos fatos que contribuem para a solução desses e de outros problemas. Enfrentamos um mundo desconhecido, não perfeitamente definido quanto aos seus objetivos. A lógica, a ética, a ciência, a filosofia e a educação precisam ser reorganizadas em harmonia com as novas situações.

A lição que fica guardada é a de que o principal indicador de sucesso de uma ação educativa está não no alcançar metas previamente definidas, mas em se estabelecer um processo de aprendizagem que seja participativo, emancipatório e transformador.

\section{Referências}

CAPRA, F. O ponto de mutação: a ciência, a sociedade e a cultura emergente. São Paulo: Cultrix, 1982.

CARNEIRO, S.M.M. Ética e educação: a questão ambiental. Revista de Educação PUC Campinas. Campinas, n. 22, p. 97107, jun. 2007.

CARVALHO, P. F. Impactos ambientais em paisagens urbanas: subsídio a uma nova urbanização. Disponível em <http:// www.seb-ecologia.org.br/forum/art24.htm>. Acesso em: 02/05/2010.

CORTELLA, M. S. A Ética e a produção do conhecimento hoje. PUCviva, São Paulo, n. 27, jul./set.2006. Disponível em: <http:// www.apropucsp.org.br/revista/r27_r15. htm>. Acesso em: 08/06/2011.

DEL RIO, V.; OLIVEIRA, L. Percepção ambiental: a experiência brasileira. São Paulo: Studio Nobel; São Carlos: EDUSFCar, 1996.

FERRARO, L. (Org.). Encontros e caminhos: formação de educadores(as) ambientais e coletivos educadores. Brasília: Diretoria de Educação Ambiental, MMA, 2005.

FRANCO, M. et al. Utilização da fotografia na construção de material didático interativo na educação a distância. Rio de Janeiro: Universidade Federal do Rio de Janeiro, 2006. (Projeto).

FREIRE, P. Pedagogia da autonomia: saberes necessários à prática educativa. 2. ed. Rio de Janeiro: Paz e Terra, 1997.

FREIRE, P. Conscientização: teoria e prática para a libertação: uma introdução ao pensamento de Paulo Freire. 3. ed. São Paulo: Moraes, 1980. 
GADOTTI, M. Carta da terra e cultura da sustentabilidade: educando para a vida sustentável. Itália: The Earth Charter in Action Conference, 2003.

GAUDIANO, E. G. Interdisciplinaridade e educação ambiental: explorando novos territórios epistêmicos. In: SATO, M.; CARVALHO, I. Educação ambiental: pesquisa e desafios. Porto Alegre: Artmed, 2005.

GUIMARÃES, R. P. Ética e as dimensões sociais da sustentabilidade. In: FERRARO, L. (Org.). Encontros e caminhos: formação de educadores (as) ambientais e coletivos educadores. Brasília: Diretoria de Educação Ambiental, MMA, 2007.

JACOBI, P. Educação ambiental, cidadania e sustentabilidade. Cadernos de Pesquisa, n. 118, p. 189-205, mar.2003.

KILPATRICK, W.H. Educação para uma civilização em mudança. 12. ed. São Paulo: Melhoramentos, 1974.

LOUREIRO, C.F.B. Emancipação. In: FERRARO, L. (Org.). Encontros e caminhos: formação de educadores (as) ambientais e coletivos educadores. Brasília: Diretoria de Educação Ambiental, MMA, 2007.

Teoria Crítica. In: FERRARO, L. (Org.) Encontros e caminhos: formação de educadores (as) ambientais e coletivos educadores. Brasília: Diretoria de Educação Ambiental, MMA, 2005.

Premissas teóricas para uma educação ambiental transformadora. Ambiente e Educação. Rio Grande, 2003. v. 8.

MARENZI, R. C. Percepção da paisagem como ferramenta na educação ambiental. Texto. Univali, 2005.
MENEZES, L. C. Ensinar Ciências no Próximo Século. In: HAMBURGER, E. W.; MATOS, C. O desafio de ensinar ciências no século XX. São Paulo: Edusp, 2000.

NICOLA, M. P. Leitura da paisagem: uma análise do seu papel como instrumento de abordagem participativa para diagnóstico rural rápido da realidade municipal: o caso de Santa Vitória do Palmar. Rio de Janeiro, 2002. Dissertação - Universidade Federal Rural do Rio de Janeiro.

NOAL, F. A interdisciplinaridade como possibilidade metodológica e como vocação da educação ambiental (EA). In: ZAKRZEVSKI. S. B. (Org.). A educação ambiental na escola: abordagens conceituais. Erechim: EDIFAPES, 2003. Disponível em: <http://www.reasul.org.br/ mambo/files/cadernos\%20de\%20EA\%20 URI\%202003.pdf>.

OLIVEIRA, A.C.D.C., et al. Diretrizes teóricas do caderno de cidadania: cidadania e direitos humanos, estatuto da criança e do adolescente e cidadania ambiental. Florianópolis: ALESC, 2008.

PELIZZOLI, M. Ética ambiental. In: FERRARO, L. (Org.). Encontros e caminhos: formação de educadores (as) ambientais e coletivos educadores. Brasília: Diretoria de Educação Ambiental, MMA, 2007.

SOBRINHO, J.D. Formação, educação e conhecimento. In: PEREIRA, E.M.A. (Org.) Universidade e educação geral: para além da especialização. 1. ed. São Paulo: Alínea, 2007.

TRÓPIA, G. Percursos históricos de ensinar Ciências através de atividades investigativas no século XX. In: ENCONTRO NACIONAL DE PESQUISA EM EDUCAÇÃO EM CIÊNCIAS, 
Florianópolis, 2009. Disponível em: <http:// www.foco.fae.ufmg.br/pdfs/83.pdf > . Acesso em: 14 jun. 2011.

TROPPMAIR, H. Ecologia da paisagem: uma retrospectiva. In: FÓRUM DE DEBATES: ECOLOGIA DE PAISAGEM E PLANEJAMENTO AMBIENTAL, 1, São Paulo, jun., 2000. Disponível em: <http:// www.seb-ecologia.org.br/forum/art24.htm>. Acesso em: 02 jun. 2011.

WITTMANN, L. C. Educação e o devir humano: a dimensão sócio-histórica da prática social da educação. In: BOHN, H. I.; SOUZA, O. (Org.). Faces do saber: desafios à educação do futuro. Florianópolis: Insular, 2002.

Enviado em: 21/09/2011

Aceito em: 14/11/2011 